\title{
New developments in the treatment of rosacea - role of once-daily ivermectin cream
}

This article was published in the following Dove Press journal:

Clinical, Cosmetic and Investigational Dermatology

18 March 2016

Number of times this article has been viewed

\author{
Leah A Cardwell' \\ Hossein Alinia' \\ Sara Moradi Tuchayi' \\ Steven R Feldman ${ }^{1-3}$ \\ 'Department of Dermatology, \\ Center for Dermatology Research, \\ ${ }^{2}$ Department of Pathology, \\ ${ }^{3}$ Department of Public Health \\ Sciences, Wake Forest School of \\ Medicine, Winston-Salem, NC, USA
}

\begin{abstract}
Rosacea is a chronic dermatological disorder with a variety of clinical manifestations localized largely to the central face. The unclear etiology of rosacea fosters therapeutic difficulty; however, subtle clinical improvement with pharmacologic treatments of various drug categories suggests a multifactorial etiology of the disease. Factors that may contribute to disease pathogenesis include immune abnormality, vascular abnormality, neurogenic dysregulation, presence of cutaneous microorganisms, UV damage, and skin barrier dysfunction. The role of ivermectin in the treatment of rosacea may be as an anti-inflammatory and anti-parasitic agent targeting Demodex mites. In comparing topical ivermectin and metronidazole, ivermectin was more effective; this treatment modality boasted more improved quality of life, reduced lesion counts, and more favorable participant and physician assessment of disease severity. Patients who received ivermectin $1 \%$ cream had an acceptable safety profile. Ivermectin is efficacious in decreasing inflammatory lesion counts and erythema.
\end{abstract}

Keywords: papulopustular rosacea, topical ivermectin, metronidazole, azelaic acid, topical

\section{Introduction}

The unclear etiology of rosacea poses significant therapeutic difficulty. Several medications have been utilized in the treatment of rosacea; however, many of them do not yield adequate and persistent improvement. Variability in rosacea assessment methodologies has made comparison of treatment options more difficult. A standardized and reliable assessment tool is necessary to assess the adequacy of novel treatment options in the management of rosacea. ${ }^{1}$ Several exacerbating factors have been identified per patient report; however, no real standard has been ascertained. Response to medications with various mechanisms of action suggests a multifactorial etiology of the disease. Topical ivermectin has emerged as a viable treatment option, which is likely to be beneficial due to its activity as an anti-inflammatory and anti-parasitic agent targeting Demodex mites which may be colonizing the pilosebaceous units of patients with the disease. ${ }^{2,3}$

\section{Background}

Rosacea is a chronic dermatological disorder characterized by a variety of clinical manifestations localized to the central face. Four subtypes exist, including erythematotelangiectatic, papulopustular, phymatous, and ocular rosacea. The main features of erythematotelangiectatic rosacea are persistent telangiectasias and redness of the central face. Papulopustular rosacea is characterized by inflammatory papules and pustules involving the central face. In addition to the inflammatory papules and pustules that are 
characteristic of this subtype, patients with papulopustular rosacea may also experience the facial erythema and telangiectasias, which are typical of erythematotelangiectatic rosacea. The phymatous subtype is characterized by the thickening of the skin and bulbous facial features. Ocular rosacea, which may occur in the absence of cutaneous manifestations, is the rarest of the subtypes and involves eye symptoms such as redness and irritation. Rosacea is commonly observed in individuals with Fitzpatrick skin types 1 and 2; though the disease may be seen in individuals of darker skin types, the prevalence is far lower. Females over the age of 30 are most commonly affected, though the disease may also occur in younger age groups and males. ${ }^{4,5}$ Many individuals with rosacea do not receive adequate treatment due to lack of awareness, misdiagnosis, and noncompliance with prescribed medications. ${ }^{6}$

The pathogenesis of rosacea is poorly understood. Contributing factors may include immune abnormality, vascular abnormality, neurogenic dysregulation, presence of cutaneous microorganisms, ultraviolet (UV) damage, and skin barrier dysfunction. An aberrant innate immune response may lead to chronic facial inflammation and vascular abnormalities in rosacea patients through increased production of toll-like receptor 2 and matrix metalloproteinases, which facilitate the activation of cytokines and cathelicidin peptides. This hypothesis is supported by evidence of increased baseline expression of cathelicidin and kallikrein 5 (KLK5) in patients with rosacea. ${ }^{4}$ Two subfamilies within the transient receptor potential family of cation channels - vanilloid and ankyrin receptors - have activity in patients with rosacea. When activated by some of the commonly identified rosacea patient triggers, including heat, capsaicin, and inflammatory states, these receptors mediate sensory and inflammatory signaling processes that manifest as flushing and burning associated with rosacea. ${ }^{4}$ Papulopustular rosacea is a type-1 T-helper cell-mediated process with the involvement of macrophages and mast cells. Upregulation of interleukin (IL)-8 messenger RNA results in the recruitment of neutrophils manifesting clinically as inflammatory pustules. ${ }^{7}$

The presence of cutaneous microorganisms has been suggested as a factor provoking cutaneous inflammation. In $35 \%-50 \%$ of rosacea patients, the Demodex folliculorum mite load is significantly increased at the site of disease. ${ }^{3}$ However, this association is controversial because unaffected individuals may also be colonized by Demodex mites. ${ }^{8}$ In patients with papulopustular rosacea, the Demodex density tends to be higher than that of control patients with healthy skin. The mite causes a cutaneous barrier disruption by eroding the epithelium. This in turn leads to a skin hypersensitivity that is reversible when the Demodex mite density is reduced with pharmacological agents. Biopsy characteristics in a patient colonized by Demodex tend to include a dense lymphocytic infiltrate around the follicle. It is this inflammatory response that facilitates the mite's ability to traverse the epidermis and destroy the pilosebaceous unit. Ultimately, this breach stimulates an exaggerated immune response that induces the papules and pustules characteristic of papulopustular rosacea. ${ }^{9}$

Staphylococcus epidermidis, Helicobacter pylori, and Bacillus oleronius may play a role in disease development and persistence. The non-hemolytic S. epidermidis is part of normal skin flora. However, in patients with papulopustular rosacea, the isolates were found to be beta hemolytic and thus more likely to produce virulence factors that stimulate the immune system. ${ }^{10}$ It is controversial whether there is a higher prevalence of $H$. pylori seropositivity in patients with rosacea. ${ }^{11-13}$ B. oleronius, which was isolated from a Demodex mite from an individual with papulopustular rosacea, happens to be sensitive to antibiotics commonly used to treat rosacea. This finding may suggest a role of this bacterium in rosacea pathogenesis. ${ }^{14}$ The distribution of rosacea in sun-exposed areas and the reported exacerbation of disease with sun exposure have inspired the theory that ultraviolet radiation may also be a contributing factor. Ultraviolet radiation increases reactive oxygen species that in turn stimulates inflammatory cytokines such as KLK 5 and cathelicidin. ${ }^{4}$ Patients with erythematotelangiectatic and papulopustular rosacea subtypes have increased transepidermal water loss and increased reactivity to the lactic acid stinging test demonstrating impaired skin barrier function. ${ }^{15}$

Oral medications, topical medications, and light-based treatments have utility in rosacea therapy. Oral antibiotics with anti-inflammatory activity, including doxycycline, tetracycline, and minocycline, have had tremendous utility in the realm of rosacea therapy. Each of these medications has dose- and concentration-dependent antimicrobial activity; however, the anti-inflammatory activity of these medications occurs at lower doses than that which is required for antibacterial effect. This is advantageous because the therapeutic benefit of these sub-antimicrobial dose tetracyclines in the treatment of rosacea, an inflammatory skin condition, can be achieved without the risk of promoting the emergence of antibiotic-resistant bacteria. ${ }^{16}$ Isotretinoin may also be used off-label and in low doses to treat rosacea.

Topical rosacea therapies include metronidazole, azelaic acid, sodium sulfacetamide, erythromycin, oxymetazoline, calcineurin inhibitors such as pimecrolimus and tacrolimus, 
permethrin, crotamiton, and ivermectin. Metronidazole reduces reactive oxygen species and decreases oxidative tissue injury by inhibiting neutrophil-generated cytokines. It also has anti-inflammatory and immunomodulatory effects that may contribute to its efficacy in rosacea therapy. Papulopustular rosacea patients treated with metronidazole had a decrease in the mean number of papules and pustules. ${ }^{17}$ Metronidazole gel is associated with minimal side effects including mild application-site discomfort but is generally well tolerated and efficacious in the treatment of moderate to severe rosacea. ${ }^{18-20}$ Once-daily use of metronidazole cream $0.75 \%$ or $1 \%$ is efficacious and well tolerated in patients with moderate to severe rosacea. ${ }^{21}$ Metronidazole $1 \%$ cream once daily had a significantly greater reduction in lesion count as compared to control vehicle once daily as early as study week 4 . Significant differences between metronidazole $1 \%$ cream BID and the control vehicle BID were not seen until study week $10 .{ }^{22}$ Azelaic acid reduces reactive oxygen species, KLK5 and cathelicidin, inhibits microbial survival, and modulates epidermal differentiation. Azelaic acid inhibits KLK5 in keratinocytes, and application to mouse back skin suppressed KLK mRNA, cathelicidin antimicrobial peptide gene $(C A M P)$, and toll-like receptor 2 mRNA. Rosacea patients treated with azelaic acid $15 \%$ gel BID for 16 weeks had decreased CAMP mRNA in the stratum corneum by 4 weeks and gradual decrease in KLK 5 expression. ${ }^{23}$ These results may suggest a new mechanism for azelaic acid activity. However, this was not a controlled study and hence the changes seen could potentially be due to variability of disease. Twice-daily use of azelaic acid $15 \%$ gel is well tolerated, safe, and efficacious in the treatment of papulopustular rosacea, but once-daily application is economical and comparably as safe and efficacious. ${ }^{24,25}$ Various azelaic acid formulations with comparable efficacy are available and provide patients with medication vehicle options. ${ }^{26}$ Combination therapy with oral doxycycline $100 \mathrm{mg}$ BID and azelaic acid 15\% gel BID was successful in achieving $>75 \%$ reduction in inflammatory lesion counts in the majority of study subjects. Subsequent remission maintenance with azelaic acid 15\% gel BID alone was successful in $75 \%$ of subjects. ${ }^{27}$ Sodium sulfacetamide is thought to achieve its therapeutic benefit through reduction of inflammation. Non-pharmacologic therapies and cosmeceuticals also have a role in rosacea therapy. The skin affected by rosacea tends to have increased transepidermal loss of water. Thus, agents that aim to replenish the moisture of the epidermis are beneficial. Sunscreens indirectly decrease reactive oxygen species that have been indicated as an etiologic factor in individuals with rosacea. ${ }^{5,28,29}$
Topical anti-parasitic agents like ivermectin $1 \%$ cream have therapeutic benefit most likely owing to their activity against Demodex mites. Ivermectin is a macrocyclic lactone with broad-spectrum activity against multiple parasitic organisms, including onchocerciasis, strongyloidiasis, pediculosis, and scabies. Similarly, ivermectin eradicates Demodex mites that reside in the pilosebaceous units of patients with papulopustular rosacea. The anti-inflammatory effects of ivermectin are achieved through decreasing neutrophil phagocytosis and chemotaxis, inhibiting inflammatory cytokines such as IL-1b and TNF-alpha, and upregulating the anti-inflammatory cytokine IL-10., ${ }^{2,3}$ It is presumed that these are the mechanisms by which ivermectin exerts its therapeutic effect in rosacea patients. Ivermectin is metabolized hepatically by CYP3A4 and has a half-life elimination of approximately 6.5 days. Peak serum concentration is achieved at approximately 10 hours post-application. Ivermectin is categorized as Pregnancy Category C, but teratogenic effects involving the drug were observed in animal reproduction following administration of the oral drug formulation. Systemic absorption of the drug is significantly lower with use of the topical formulation as directed. ${ }^{30}$

\section{Results \\ Clinical studies}

The results of two identical 12-week duration, Phase III, randomized, double-blinded studies showed superior efficacy and comparable safety of ivermectin $1 \%$ cream applied once daily as compared to vehicle control in the treatment of papulopustular rosacea. The Investigator's Global Assessment of Rosacea Severity (IGA-RS) was used as the efficacy assessment parameter. The achievement of IGA success, defined by the study as "clear" or "almost clear" rosacea severity grades, was $38.4 \%$ and $40.1 \%$ for study 1 and study 2 , respectively, with the use of ivermectin $1 \%$ compared to $11.6 \%$ and $18.8 \%$ for study 1 and study 2 , respectively, with the use of the vehicle control. Safety of the ivermectin $1 \%$ cream was assessed by incidence of adverse events. The incidence of adverse events with the use of ivermectin $1 \%$ cream versus the use of the vehicle control was comparable in studies 1 and 2. For ivermectin 1\%, the incidence of adverse events in studies 1 and 2 was $40.5 \%$ and $36.5 \%$, respectively. For the vehicle control, the incidence of adverse events in studies 1 and 2 was $39.4 \%$ and $36.5 \%$, respectively. ${ }^{2}$ In a 40-week, investigator-blinded, active controlled extension of the aforementioned studies 1 and 2, subjects who initially received ivermectin $1 \%$ cream once daily continued this regimen while subjects who initially received the vehicle 
Table I Clinical studies and case reports

\begin{tabular}{|c|c|c|c|c|c|c|}
\hline $\begin{array}{l}\text { Study } \\
\text { reference }\end{array}$ & Patient characteristics & $\begin{array}{l}\text { Number of } \\
\text { participants }\end{array}$ & $\begin{array}{l}\text { Medication } \\
\text { regimen }\end{array}$ & Study design & $\begin{array}{l}\text { Study } \\
\text { duration }\end{array}$ & Findings \\
\hline $\begin{array}{l}\text { Stein } \\
\text { et } \mathrm{al}^{2}\end{array}$ & $\begin{array}{l}\text { Subjects > I8-year-old } \\
\text { males and females; } \\
\text { moderate to severe } \\
\text { PPR based on } \\
\text { IGA; I5-70 facial } \\
\text { inflammatory lesions }\end{array}$ & $\begin{array}{l}\text { Study I - } 683 \\
\text { Study } 2-688\end{array}$ & $\begin{array}{l}\text { IVM I\% cream } \\
\text { once daily vs } \\
\text { vehicle cream } \\
\text { once daily }\end{array}$ & $\begin{array}{l}\text { Two multicenter } \\
\text { studies of identical } \\
\text { design (study I } \\
\text { and study 2), } \\
\text { randomized, } \\
\text { double-blinded, } \\
\text { parallel, vehicle } \\
\text { controlled }\end{array}$ & 12 weeks & $\begin{array}{l}\text { IGA success rate } \\
\text { IVM I\% cream } \\
\text { Study I - 38.4\% } \\
\text { Study } 2-40.1 \% \\
\text { VC } \\
\text { Study I - II.6\% } \\
\text { Study } 2-18.8 \% \\
\text { Adverse events } \\
\text { incidence } \\
\text { IVM I\% cream } \\
\text { Study I - 40.5\% } \\
\text { Study } 2-36.5 \% \\
\text { VC } \\
\text { Study I - 39.4\% } \\
\text { Study } 2-36.5 \%\end{array}$ \\
\hline $\begin{array}{l}\text { Stein Gold } \\
\text { et } \mathrm{al}^{31}\end{array}$ & $\begin{array}{l}\text { Subjects > I8-year-old } \\
\text { males and females; } \\
\text { moderate to severe } \\
\text { PPR based on IGA; } \\
\text { I5-70 facial } \\
\text { inflammatory lesions }\end{array}$ & $\begin{array}{l}\text { Study I - } 622 \\
\text { Study } 2-636\end{array}$ & $\begin{array}{l}\text { IVM I\% cream } \\
\text { once daily vs } \\
\text { AzA I5\% gel BID }\end{array}$ & $\begin{array}{l}\text { Extension of the } \\
\text { above study; initial } \\
\text { IVM I\% cream } \\
\text { groups continued } \\
\text { IVM regimen; } \\
\text { initial vehicle } \\
\text { cream control } \\
\text { group switched } \\
\text { to AzA I5\% gel } \\
\text { twice daily }\end{array}$ & 40 weeks & $\begin{array}{l}\text { IVM I\% cream showed } \\
\text { increased efficacy in study } \\
\text { I and study } 2 \\
\text { IGA success rate } \\
\text { IVM I\% cream } \\
\text { Study I - increased from } \\
38.4 \% \text { to } 7 \text { I. I\% during } \\
\text { study duration } \\
\text { Study } 2 \text { - increased from } \\
40.1 \% \text { to } 76.0 \% \text { during } \\
\text { study duration } \\
\text { Adverse events } \\
\text { IVM I\% cream } \\
\text { Majority who received } \\
\text { this treatment in both } \\
\text { study I and study } 2 \text { denied } \\
\text { treatment-associated } \\
\text { stinging, burning, dryness, } \\
\text { or itching } \\
\text { AzA I5\% gel } \\
\text { More patients who } \\
\text { received this treatment } \\
\text { in both study I and study } 2 \\
\text { reported treatment- } \\
\text { associated stinging, } \\
\text { burning, dryness, or itching }\end{array}$ \\
\hline $\begin{array}{l}\text { Taieb } \\
\text { et } \mathrm{al}^{32}\end{array}$ & $\begin{array}{l}\text { Subjects }>\text { |8-year-old } \\
\text { males and females; } \\
\text { moderate to severe } \\
\text { PPR }\end{array}$ & 960 & $\begin{array}{l}\text { IVM I } \% \text { cream } \\
\text { once daily vs } \\
\text { MTZ } 0.75 \% \text { cream } \\
\text { twice daily }\end{array}$ & $\begin{array}{l}\text { Investigator- } \\
\text { blinded, } \\
\text { randomized, } \\
\text { parallel group } \\
\text { study }\end{array}$ & 16 weeks & $\begin{array}{l}\text { Percentage reduction of } \\
\text { inflammatory lesions } \\
\text { IVM I } \% \text { cream } 83.0 \% \\
\text { MTZ } 0.75 \% \text { cream } 73.7 \% \\
\text { IGA success rates } \\
\text { IVM I } \% \text { cream } 84.9 \% \\
\text { MTZ } 0.75 \% \text { cream } 75.4 \% \\
\text { Safety profile } \\
\text { Comparable between IVM } \\
\text { I\% cream and MTZ } 0.75 \% \\
\text { cream. Skin irritation was the } \\
\text { most common adverse event }\end{array}$ \\
\hline $\begin{array}{l}\text { de Macedo } \\
\text { et } \mathrm{a}^{35}\end{array}$ & $\begin{array}{l}4 \text { I-year-old female; } \\
\text { gnatophyma } \\
\text { (phymatous rosacea } \\
\text { affecting chin) } \times 2 \text { years }\end{array}$ & I & $\begin{array}{l}\text { Single dose, oral } \\
\text { IVM I } 2 \text { mg, } \\
\text { TCN I g/d, } \\
\text { MTZ I\% cream }\end{array}$ & Case report & $N / A$ & $\begin{array}{l}\text { Clinical improvement } \\
\text { observed at I-month } \\
\text { follow-up }\end{array}$ \\
\hline
\end{tabular}


Table I (Continued)

\begin{tabular}{|c|c|c|c|c|c|c|}
\hline $\begin{array}{l}\text { Study } \\
\text { reference }\end{array}$ & Patient characteristics & $\begin{array}{l}\text { Number of } \\
\text { participants }\end{array}$ & $\begin{array}{l}\text { Medication } \\
\text { regimen }\end{array}$ & Study design & $\begin{array}{l}\text { Study } \\
\text { duration }\end{array}$ & Findings \\
\hline $\begin{array}{l}\text { Brown } \\
\text { et a }\left.\right|^{33}\end{array}$ & $\begin{array}{l}\text { I2-year-old female; } \\
\text { Demodex folliculorum- } \\
\text { associated severe } \\
\text { recalcitrant } \\
\text { oculocutaneous } \\
\text { rosacea }\end{array}$ & 1 & $\begin{array}{l}\text { Single dose, } \\
\text { oral IVM I } 2 \mathrm{mg} \\
(250 \mu \mathrm{g} / \mathrm{kg})\end{array}$ & Case report & $N / A$ & $\begin{array}{l}\text { Marked improvement in } \\
\text { cutaneous symptoms at } \\
\text { I-month follow-up with } \\
\text { progressive resolution } \\
\text { without additional } \\
\text { treatments. Ocular symptom } \\
\text { resolution. No recurrence } \\
\text { at } 2 \text {-year follow-up }\end{array}$ \\
\hline $\begin{array}{l}\text { Allen } \\
\text { et } \mathrm{al}^{34}\end{array}$ & $\begin{array}{l}68 \text {-year-old male; } \\
\text { recalcitrant PPR } \times \\
6 \text { years, rosacea-like } \\
\text { demodicosis }\end{array}$ & 1 & $\begin{array}{l}\text { Oral IVM } 3 \mathrm{mg} \\
\text { daily } \times 8 \text { days, } \\
\text { permethrin cream } \\
3 \text { times weekly } \times \\
2 \text { weeks (continued } \\
\text { for } 3 \text { months for } \\
\text { maintenance) }\end{array}$ & Case report & N/A & Marked clinical improvement \\
\hline $\begin{array}{l}\text { Forstinger } \\
\text { et } \mathrm{al}^{39}\end{array}$ & $\begin{array}{l}32 \text {-year-old male; } \\
\text { rosacea-like } \\
\text { demodicidosis } \times \\
4 \text { years, refractory to } \\
\text { conventional treatment }\end{array}$ & 1 & $\begin{array}{l}\text { Single dose, } \\
\text { oral IVM } 200 \mu g / k g \text {, } \\
\text { subsequent weekly } \\
\text { topical permethrin } \\
\text { cream }\end{array}$ & Case report & $N / A$ & $\begin{array}{l}\text { Reduction of pruritus within } \\
2 \text { weeks, reduction of } \\
\text { inflammation within } 4 \text { weeks }\end{array}$ \\
\hline $\begin{array}{l}\text { Guerrero- } \\
\text { Gonzalez } \\
\text { et al }{ }^{40}\end{array}$ & $\begin{array}{l}\text { 7-year-old female; } \\
\text { crusted, rosacea-like } \\
\text { demodicosis }\end{array}$ & 1 & $\begin{array}{l}\text { Oral IVM } 200 \mu \mathrm{g} / \mathrm{kg} \\
\text { weekly for } 10 \text { doses, } \\
\text { permethrin } 5 \% \\
\text { lotion, } 30 \mathrm{mg} / \mathrm{kg} \\
\text { oral erythromycin } \\
\text { divided into } \\
\text { three doses } \\
\text { (then continued } \\
\text { for } 2 \text { months), } \\
\text { metronidazole } \\
\text { cream }\end{array}$ & Case report & $\mathrm{N} / \mathrm{A}$ & $\begin{array}{l}\text { Clinical resolution after } \\
3 \text { months of treatment }\end{array}$ \\
\hline
\end{tabular}

Abbreviations: AzA, azelaic acid; IVM, ivermectin; VC, vehicle control; MTZ, metronidazole; TCN, tetracycline; IGA, Investigator's Global Assessment of Rosacea Severity; PPR, papulopustular rosacea; BID, twice daily; N/A, not applicable.

cream control once daily switched to azelaic acid $15 \%$ gel twice daily. In studies 1 and 2, ivermectin 1\% cream showed increasing efficacy from week 12 to week 52 . In study 1 , the percentage of patients with IGA score of "clear" or "almost clear" increased from $38.4 \%$ at week 12 to $71.1 \%$ at week 52. In study 2, the percentage of patients with IGA score of "clear" or "almost clear" increased from $40.1 \%$ at week 12 to $76.0 \%$ at week 52 . Most of the patients who received ivermectin $1 \%$ cream in either study 1 or study 2 denied stinging, burning, dryness, or itching associated with the medication, whereas more subjects who received azelaic acid $15 \%$ gel twice daily reported these symptoms. The initial and follow-up studies demonstrated that ivermectin $1 \%$ cream is an appropriate long-term therapy for papulopustular rosacea as the medication was effective and safe for 52 weeks of treatment. ${ }^{2,31}$

A Phase III, investigator-blinded, randomized, parallelgroup study assessed the superiority of ivermectin $1 \%$ cream applied once daily versus metronidazole $0.75 \%$ cream applied twice daily for the treatment of rosacea inflammatory lesions. Ivermectin $1 \%$ cream was superior to metronidazole $0.75 \%$ cream. Percentage reduction of inflammatory lesions from baseline was $83.0 \%$ for ivermectin $1 \%$ cream and $73.7 \%$ for metronidazole $0.75 \%$ cream. IGA success rates, defined as "clear" or "almost clear", were $84.9 \%$ for ivermectin $1 \%$ cream and $75.4 \%$ for metronidazole $0.75 \%$ cream. Safety of ivermectin $1 \%$ cream versus metronidazole $0.75 \%$ cream was comparable as the incidence of adverse events was similar between each group, with the most common adverse event being skin irritation (Table 1). ${ }^{32}$

\section{Case reports}

Ivermectin, both oral and topical, has been effective in treating rosacea of various subtypes. In particular, a case of recalcitrant oculocutaneous rosacea in an immunocompetent patient with Demodex folliculorum colonization 
achieved resolution with a single dose of oral ivermectin. ${ }^{33}$ An individual with recalcitrant papulopustular rosacea and evidence of numerous Demodex organisms on histologic examination benefited from oral ivermectin and topical permethrin cream. ${ }^{34}$ Gnatophyma, a rare variant of phymatous rosacea involving the chin, was treated with oral ivermectin, oral tetracycline, and metronidazole cream with satisfactory results (Table 1$).{ }^{35}$

\section{Patient-focused perspectives}

Stein et al reported that in studies 1 and 2 after treatment with ivermectin $1 \%$ cream, $34 \%$ and $32.0 \%$ of subjects, respectively, rated their improvement as "excellent". ${ }^{2}$ Only $9.5 \%$ and $7.3 \%$ of the subjects treated with the vehicle control in studies 1 and 2, respectively, reported "excellent" improvement. ${ }^{2}$ Taieb et al showed that $85.5 \%$ of subjects in the ivermectin $1 \%$ treatment arm versus $74.8 \%$ of subjects in the metronidazole $0.75 \%$ treatment arm reported "excellent" or "good" global improvement in their rosacea. ${ }^{32}$ Patients in the ivermectin $1 \%$ cream group had a higher reduction in their Dermatology Quality of Life Index (DLQI) score than the metronidazole $0.75 \%$ cream group, meaning subjects in the ivermectin $1 \%$ cream group had a greater improvement in quality of life. ${ }^{32}$

\section{Conclusion}

Rosacea poses a therapeutic challenge owing to its likely multifactorial pathogenesis. Rosacea patients tend to be more sensitive to topical treatments and may experience skin irritation with use; noncompliance with the treatment regimen may occur as a result. Despite being a topical treatment, ivermectin cream has a relatively low side effect profile. In comparing ivermectin cream and metronidazole cream, ivermectin was more effective; this treatment modality boasted more improved quality of life, reduced lesion counts, and more favorable participant and physician assessment of disease severity ${ }^{32,36}$ Metronidazole $0.75 \%$ gel was inferior to azelaic acid $15 \%$ gel in reducing inflammatory lesions and erythema. ${ }^{37}$ Metronidazole $0.75 \%$ cream and azelaic acid 20\% cream induced significant and near-equal reduction in papules and pustules, but patients reported greater satisfaction with azelaic acid. ${ }^{38}$ Further studies are needed to compare the efficacy of topical ivermectin and azelaic acid gel in the treatment of papulopustular rosacea. Though the exact mechanism of action of ivermectin in improving rosacea is unknown, it is presumed that the anti-inflammatory and anti-parasitic activities of the medication target the etiologic factors of the disease.

\section{Disclosure}

Steven R Feldman is a speaker for Janssen and Taro. He is a consultant and speaker for Galderma, Stiefel/GlaxoSmithKline, Abbott Labs, and Leo Pharma Inc. Steven R Feldman has received grants from Galderma, Janssen, Abbott Labs, Amgen, Stiefel/GlaxoSmithKline, Celgene, and Anacor. $\mathrm{He}$ is a consultant for Amgen, Baxter, Caremark, Gerson Lehrman Group, Guidepoint Global, Hanall Pharmaceutical Co Ltd, Kikaku, Lilly, Merck and Co Inc, Merz Pharmaceuticals, Mylan, Novartis Pharmaceuticals, Pfizer Inc, Qurient, Suncare Research, and Xenoport. He is on an advisory board for Pfizer Inc. Steven R Feldman is the founder and holds stock in Causa Research and holds stock and is majority owner in Medical Quality Enhancement Corporation. He receives Royalties from UpToDate and Xlibris. Leah A Cardwell, Sara Moradi Tuchayi, and Hossein Alinia have no conflicts of interest to disclose in this work.

\section{References}

1. Hopkinson D, Moradi Tuchayi S, Alinia H, Feldman SR. Assessment of rosacea severity: a review of evaluation methods used in clinical trials. J Am Acad Dermatol. 2015;73(1):138-143.

2. Stein L, Kircik L, Fowler J, et al. Efficacy and safety of ivermectin 1\% cream in treatment of papulopustular rosacea: results of two randomized, double-blind, vehicle-controlled pivotal studies. J Drugs Dermatol. 2014;13(3):316-323.

3. Abokwidir M, Fleischer AB. An emerging treatment: topical ivermectin for papulopustular rosacea. J Dermatolog Treat. 2015;30:1-2.

4. Two AM, Wu W, Gallo RL, Hata TR. Rosacea: part I. Introduction, categorization, histology, pathogenesis, and risk factors. J Am Acad Dermatol. 2015;72(5):749-758; quiz 759-760.

5. Two AM, Wu W, Gallo RL, Hata TR. Rosacea: part II. Topical and systemic therapies in the treatment of rosacea. J Am Acad Dermatol. 2015;72(5):761-770; quiz 771-772.

6. Davis SA, Feldman SR. Patterns of ambulatory care usage and leading treatments for rosacea. J Dermatolog Treat. 2014;25(4):275-277.

7. Steinhoff M, Schauber J, Leyden JJ. New insights into rosacea pathophysiology: a review of recent findings. J Am Acad Dermatol. 2013;69(6 Suppl 1):S15-S26.

8. Ali ST, Alinia H, Feldman SR. The treatment of rosacea with topical ivermectin. Drugs Today (Barc). 2015;51(4):243-250.

9. Forton FM. Papulopustular rosacea, skin immunity and Demodex: pityriasis folliculorum as a missing link. JEur Acad Dermatol Venereol. 2012;26(1):19-28.

10. Dahl MV, Ross AJ, Schlievert PM. Temperature regulates bacterial protein production: possible role in rosacea. $J$ Am Acad Dermatol. 2005;52(1):182.

11. Lazaridou E, Giannopoulou C, Fotiadou C, Vakirlis E, Trigoni A, Ioannides D. The potential role of microorganisms in the development of rosacea. J Dtsch Dermatol Ges. 2011;9(1):21-25.

12. Tüzün Y, Keskin S, Kote E. The role of Helicobacter pylori infection in skin diseases: facts and controversies. Clin Dermatol. 2010;28(5): 478-482.

13. Mc Aleer MA, Lacey N, Powell FC. The pathophysiology of rosacea. G Ital Dermatol Venereol. 2009;144(6):663-671.

14. Jarmuda S, O’Reilly N, Zaba R, Jakubowicz O, Szkaradkiewicz A, Kavanagh K. Potential role of Demodex mites and bacteria in the induction of rosacea. J Med Microbiol. 2012;61(Pt 11):1504-1510. 
15. Dirschka T, Tronnier H, Fölster-Holst R. Epithelial barrier function and atopic diathesis in rosacea and perioral dermatitis. Br J Dermatol. 2004;150(6):1136-1141.

16. Layton A, Thiboutot D. Emerging therapies in rosacea. $\mathrm{J} \mathrm{Am} \mathrm{Acad}$ Dermatol. 2013;69(6 Suppl 1):S57-S65.

17. McClellan KJ, Noble S. Topical metronidazole. A review of its use in rosacea. Am J Clin Dermatol. 2000;1(3):191-199.

18. Wolf JE, Jr, Kerrouche N, Arsonnaud S. Efficacy and safety of once-daily metronidazole $1 \%$ gel compared with twice-daily azelaic acid $15 \%$ gel in the treatment of rosacea. Cutis. 2006;77(4 Suppl):3-11.

19. Wolf JE, Jr, Del Rosso JQ. The CLEAR trial: results of a large community-based study of metronidazole gel in rosacea. Cutis. 2007;79(1):73-80.

20. Bleicher PA, Charles JH, Sober AJ. Topical metronidazole therapy for rosacea. Arch Dermatol. 1987;123(5):609-614.

21. Dahl MV, Jarratt M, Kaplan D, Tuley MR, Baker MD. Once-daily topical metronidazole cream formulations in the treatment of the papules and pustules of rosacea. J Am Acad Dermatol. 2001;45(5): 723-730.

22. Jorizzo JL, Lebwohl M, Tobey RE. The efficacy of metronidazole $1 \%$ cream once daily compared with metronidazole $1 \%$ cream twice daily and their vehicles in rosacea: a double-blind clinical trial. J Am Acad Dermatol. 1998;39(3):502-504.

23. Coda AB, Hata T, Miller J, et al. Cathelicidin, kallikrein 5, and serine protease activity is inhibited during treatment of rosacea with azelaic acid 15\% gel. J Am Acad Dermatol. 2013;69(4):570-577.

24. Thiboutot D, Thieroff-Ekerdt R, Graupe K. Efficacy and safety of azelaic acid $(15 \%)$ gel as a new treatment for papulopustular rosacea: results from two vehicle-controlled, randomized phase III studies. J Am Acad Dermatol. 2003;48(6):836-845.

25. Thiboutot DM, Fleischer AB Jr, Del Rosso JQ, Graupe K. Azelaic acid $15 \%$ gel once daily versus twice daily in papulopustular rosacea. J Drugs Dermatol. 2008;7(6):541-546.

26. Draelos ZD, Elewski B, Staedtler G, Havlickova B. Azelaic acid foam $15 \%$ in the treatment of papulopustular rosacea: a randomized, doubleblind, vehicle-controlled study. Cutis. 2013;92(6):306-317.

27. Thiboutot DM, Fleischer AB, Del Rosso JQ, Rich P. A multicenter study of topical azelaic acid 15\% gel in combination with oral doxycycline as initial therapy and azelaic acid 15\% gel as maintenance monotherapy. J Drugs Dermatol. 2009;8(7):639-648.
28. Sarnoff DS. Therapeutic update on rosacea. J Drugs Dermatol. 2014;13(1):10-11.

29. Moustafa FA, Sandoval LF, Feldman SR. Rosacea: new and emerging treatments. Drugs. 2014;74(13):1457-1465.

30. Ivermectin cream (Soolantra) for rosacea. Med Lett Drugs Ther. 201513;57(1466):51-52.

31. Stein Gold L, Kircik L, Fowler J, et al. Long-term safety of ivermectin $1 \%$ cream vs azelaic acid $15 \%$ gel in treating inflammatory lesions of rosacea: results of two 40-week controlled, investigator-blinded trials. J Drugs Dermatol. 2014;13(11):1380-1386.

32. Taieb A, Ortonne JP, Ruzicka T, et al. Superiority of ivermectin 1\% cream over metronidazole $0 \cdot 75 \%$ cream in treating inflammatory lesions of rosacea: a randomized, investigator-blinded trial. $\mathrm{Br} J$ Dermatol. 2015;172(4):1103-1110.

33. Brown M, Hernández-Martín A, Clement A, Colmenero I, Torrelo A. Severe Demodex folliculorum-associated oculocutaneous rosacea in a girl successfully treated with ivermectin. JAMA Dermatol. 2014;150(1):61-63.

34. Allen KJ, Davis CL, Billings SD, Mousdicas N. Recalcitrant papulopustular rosacea in an immunocompetent patient responding to combination therapy with oral ivermectin and topical permethrin. Cutis. 2007;80(2):149-151.

35. de Macedo AC, Sakai FD, de Vasconcelos RC, Duarte AA. Gnatophyma a rare form of rosacea. An Bras Dermatol. 2012;87(6):903-905.

36. van Zuuren EJ, Fedorowicz Z. Interventions for rosacea: abridged updated Cochrane systematic review including GRADE assessments. Br J Dermatol. 2015;173(3):651-652.

37. Elewski BE, Fleischer AB, Jr, Pariser DM. A comparison of $15 \%$ azelaic acid gel and $0.75 \%$ metronidazole gel in the topical treatment of papulopustular rosacea: results of a randomized trial. Arch Dermatol. 2003;139(11):1444-1450.

38. Maddin S. A comparison of topical azelaic acid $20 \%$ cream and topical metronidazole $0.75 \%$ cream in the treatment of patients with papulopustular rosacea. J Am Acad Dermatol. 1999;40(6 Pt 1):961-965.

39. Forstinger C, Kittler H, Binder M. Treatment of rosacea-like demodicidosis with oral ivermectin and topical permethrin cream. J Am Acad Dermatol. 1999;41(5 Pt 1):775-777.

40. Guerrero-González GA, Herz-Ruelas ME, Gómez-Flores M, OcampoCandiani J. Crusted demodicosis in an immunocompetent pediatric patient. Case Rep Dermatol Med. 2014;2014:458046.
Clinical, Cosmetic and Investigational Dermatology

\section{Publish your work in this journal}

Clinical, Cosmetic and Investigational Dermatology is an international, peer-reviewed, open access, online journal that focuses on the latest clinical and experimental research in all aspects of skin disease and cosmetic interventions. All areas of dermatology will be covered; contributions will be welcomed from all clinicians and

\section{Dovepress}

basic science researchers globally. This journal is indexed on CAS. The manuscript management system is completely online and includes a very quick and fair peer-review system, which is all easy to use. Visit http://www.dovepress.com/testimonials.php to read real quotes from published authors. 